\title{
Isolation and Characterization of a Mutant of Pseudomonas aureofaciens ATCC 15926 with an Increased Capacity for Synthesis of Pyrrolnitrin
}

\author{
By OLGA SALCHER AND FRANZ LINGENS* \\ Institut für Mikrobiologie, Universität Hohenheim, Garbenstrasse 30, \\ D-7000 Stuttgart 70, Federal Republic of Germany
}

(Received 11 September 1979; revised 29 October 1979)

\begin{abstract}
A mutant having a 30 -fold increased ability to synthesize pyrrolnitrin was isolated from Pseudomonas aureofaciens ATCC 15926 after mutagenesis with $N$-methyl- $N$ '-nitro- $N$ nitrosoguanidine. The mutant strain also differed from the parent strain in pigmentation and in its inability to catabolize anthranilic acid and the benzene moiety of tryptophan and kynurenine.
\end{abstract}

\section{INTRODUCTION}

Pyrrolnitrin, an antifungal antibiotic, is produced by several pseudomonads (Arima et al., 1964; Elander et al., 1968). Biosynthetic studies with Pseudomonas aureofaciens (Lilly A 10338.5) ATCC 15926 have shown that tryptophan is the direct precursor of pyrrolnitrin (Lively et al., 1967; Martin et al., 1972), although whether it is the D- or the L-isomer that is the precursor has not been determined. Cultures supplemented with D-tryptophan yielded increased amounts of the antibiotic (Hamill et al., 1967). This fact led to the isolation of tryptophan analogue-resistant mutants (Elander et al., 1971). In strains resistant to 5-DLfluorotryptophan and 6-DL-fluorotryptophan the regulatory pattern of tryptophan synthesis is supposed to be altered leading to an increase in pyrrolnitrin formation (Elander, 1976; Drew \& Demain, 1977).

During our studies on pyrrolnitrin biosynthesis we found that a minimal medium should be used for the growth of $P$. aureofaciens ATCC 15926 instead of a complete medium, because undefined ingredients could interfere with experiments on pyrrolnitrin formation. However, under these conditions very low concentrations of the antibiotic $\left(<0.3 \mu \mathrm{g} \mathrm{ml}^{-1}\right)$ were produced. To facilitate further studies, we have tried to increase pyrrolnitrin production by optimizing the growth medium (Auden et al., 1967) and by mutation. While variation of the components of the medium did not enhance the production of pyrrolnitrin, mutagenesis was successful. In this paper we report on a comparison between the wild-type strain and a mutant with increased capacity for pyrrolnitrin formation.

\section{METHODS}

Organisms and growth conditions. Pseudomonas aureofaciens ATCC 15926 was the parent strain. The derived mutant was designated $P$. aureofaciens ACN (anthranilate catabolism negative).

The bacteria were maintained on the complete medium described by Lysenko (1961). For nutritional studies and evaluation of pyrrolnitrin production a minimal medium was used containing $\left(\mathrm{g} \mathrm{l}^{-1}\right)$ : glycerol, $30 ; \mathrm{K}_{2} \mathrm{HPO}_{4}, 3 ; \mathrm{KH}_{2} \mathrm{PO}_{4}, 0 \cdot 5 ;\left(\mathrm{NH}_{4}\right)_{2} \mathrm{SO}_{4}, 1 ; \mathrm{MgSO}_{4} .7 \mathrm{H}_{2} \mathrm{O}, 0.5 ; \mathrm{NaCl}, 5 ; \mathrm{pH} 7 \cdot 0$. Supplements or other carbon sources replacing glycerol were added at a final concentration of $3 \mathrm{~mm}$. Solid media contained $1.7 \%$ $(\mathrm{w} / \mathrm{v})$ agar (Merck).

The bacteria were grown in the dark at $30^{\circ} \mathrm{C}$ in shaken 21 Erlenmcyer flasks containing $500 \mathrm{ml}$ medium. The inoculum ( $50 \mathrm{ml}$ per $500 \mathrm{ml}$ medium) was taken from an exponentially growing culture (approx. $1 \times 10^{8}$ 
cells $\mathrm{ml}^{-1}$ ). The turbidity of the cultures was measured in an Eppendorf photometer at $578 \mathrm{~nm}$. During growth, production of pyrrolnitrin was monitored by thin-layer chromatography and by a quantitative bioassay.

Microbial assay of pyrrolnitrin. Pyrrolnitrin was assayed using the agar-well diffusion technique, with Neurospora crassa ATCC 9276 as the test organism according to the method of Gordee \& Westhead (1972). Complete agar (see above) containing $10^{5} \mathrm{~N}$. crassa spores $\mathrm{ml}^{-1}$ was designated $\mathrm{NC}$-agar. $\mathrm{NC}$-agar was also used for the qualitative estimation of antibiotic activity produced by replica-plated colonies. Colonies of $P$. aureofaciens ATCC 15926 caused only inhibition of conidiation of $N$. crassa on NC-agar. The minimal inhibitory concentration of pyrrolnitrin was $0 \cdot 3 \mu \mathrm{g} \mathrm{ml}^{-1}$.

Conditions for mutagenesis and isolation of mutants. For mutagenesis the method of Adelberg et al. (1965)

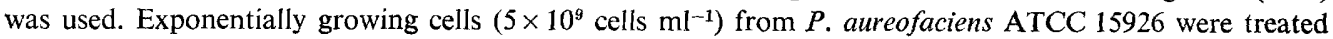
with $N$-methyl- $N^{\prime}$-nitro- $N$-nitrosoguanidine (MNNG) at a final concentration of $20 \mu \mathrm{g} \mathrm{ml}^{-1}$ in $0.1 \mathrm{M}$ $\mathrm{KH}_{2} \mathrm{PO}_{4} / \mathrm{K}_{2} \mathrm{HPO}_{4}$ buffer pH 7.0. Cells at $5 \%$ survival (after $8 \mathrm{~min}$ ) were plated in appropriate dilution on complete agar. After incubation at $30^{\circ} \mathrm{C}$, colonies with a diameter of 2 to $3 \mathrm{~mm}$ were replica-plated on to minimal agar, complete agar and $\mathrm{NC}$-agar.

Mutants producing increased amounts of pyrrolnitrin were detected on NC-agar by the zones of inhibition (approx. diam. 5 to $7 \mathrm{~mm}$ ) surrounding them. After cloning, mutants were grown in minimal medium for $5 \mathrm{~d}$ and assayed quantitatively for pyrrolnitrin production. The strain with the highest production capacity was further characterized by comparison with the parent strain. Standard methods were employed for morphological and physiological studies (Society of American Bacteriologists, 1957; Skerman, 1967).

Extraction and isolation of metabolites. After $5 \mathrm{~d}$ incubation, cultures in minimal medium were extracted with 1 vol. ethyl acetate at $\mathrm{pH}$ 5.5. The organic layer was separated and concentrated in vacuo to one-tenth of its original volume. A sample $(50 \mu \mathrm{l})$ was applied to a silica gel 60 plate and co-chromatographed with authentic aminopyrrolnitrin, anthranilic acid, indole-3-acetic acid, phenazine-1-carboxylic acid and pyrrolnitrin (each $0.01 \%, \mathrm{w} / \mathrm{v}$, in propan-2-ol). Aminopyrrolnitrin and pyrrolnitrin were separated using benzene as solvent, with $R_{F}$ values of 0.29 and 0.62 , respectively. Separation of the other compounds was achieved using ethyl acetate/propan-2-ol/water (65:24:11, by vol.) as solvent, with the following $R_{F}$ values: anthranilic acid, 0.87 ; indole-3-acetic acid, 0.79 ; phenazine-1-carboxylic acid, 0.59 . The corresponding migration positions were detected under u.v. light at $254 \mathrm{~nm}$ and by spraying with Van Urk's reagent (Stahl \& Kaldewey, 1961). Ethyl acetate extracts were applied to a silica gel 60 column $(80 \times 5 \mathrm{~cm})$ to obtain a larger amount of metabolites for spectroscopic studies. Further purification procedures were carried out as described previously (Salcher et al., 1978).

Analytical procedures. Ultraviolet spectra were measured by the Spectralphotometer DMR 21 (Zeiss, Oberkochen, F.R.G.). Infrared spectra of metabolites in $\mathrm{KBr}$ discs were recorded using a Leitz spectrograph (Leitz, Wetzlar, F.R.G.). Mass spectra were obtained with a Varian MAT 311 (Varian, Bremen, F.R.G.) instrument (ionizing voltage $90 \mathrm{eV}$ ).

Chemicals and biochemicals. All compounds were of the highest purity grade available. Aminopyrrolnitrin was prepared from pyrrolnitrin by reduction with sodium dithionite under alkaline conditions (Schröter, 1957). Pyrrolnitrin was a gift from Ciba-Geigy, Basel, Switzerland. Silica gel 60 (230 to 400 mesh ASTM) was purchased from Merck, Darmstadt, F.R.G., and silica gel $60 \mathrm{~F}_{254}$ plates $(0.25 \mathrm{~mm}$ thickness) were obtained from Macherey-Nagel \& Co., Düren, F.R.G. MNNG was kindly supplied by Dr R. Süssmuth, Institute of Microbiology, Hohenheim, F.R.G. Phenazine-1-carboxylic acid was a gift from Professor U. Hollstein, Albuquerque, U.S.A. Multodiscs for testing antibiotic sensitivity were purchased from Oxoid.

\section{RESULTS AND DISCUSSION}

Among $3 \times 10^{4}$ colonies examined, five colonies with distinct inhibition zones were detected on NC-agar. Pyrrolnitrin concentrations, determined by the quantitative bioassay, ranged from 0.8 to $7 \mu \mathrm{g} \mathrm{ml}^{-1}$. One isolate $\left(P\right.$. aureofaciens $\mathrm{ACN}$ ) formed $9 \mu \mathrm{g} \mathrm{ml}^{-1}$ in liquid culture. The increased production was stable during cloning and growth studies. Under the test conditions used pyrrolnitrin was formed in the stationary growth phase (Fig. 1).

Several phenotypic properties of the mutant strain $P$. aureofaciens $\mathrm{ACN}$ were compared with those of the parent strain, $P$. aureofaciens ATCC 15926. Both strains showed the morphological and physiological characteristics listed for $P$. aureofaciens in Bergey's Manual (Buchanan \& Gibbons, 1974) except that nitrate was not reduced to nitrite. Their antibiograms were identical. The bacteria were inhibited by colistin sulphate $(10 \mu \mathrm{g})$, kanamycin $(5 \mu \mathrm{g})$, neomycin $(10 \mu \mathrm{g})$, streptomycin $(10 \mu \mathrm{g})$ and tetracycline $(10 \mu \mathrm{g})$. They were resistant to ampicillin $(2 \mu \mathrm{g})$, cephaloridine $(5 \mu \mathrm{g})$, chloramphenicol $(10 \mu \mathrm{g})$, cloxacillin $(5 \mu \mathrm{g})$, erythromycin $(10 \mu \mathrm{g})$, fusidic acid $(10 \mu \mathrm{g})$, lincomycin $(2 \mu \mathrm{g})$, methicillin $(10 \mu \mathrm{g})$, novobiocin $(5 \mu \mathrm{g})$, penicillin $\mathrm{G}(1 \cdot 5 \mathrm{i} . \mathrm{u}$.$) , and sulphafurazole (100 \mu \mathrm{g})$. 


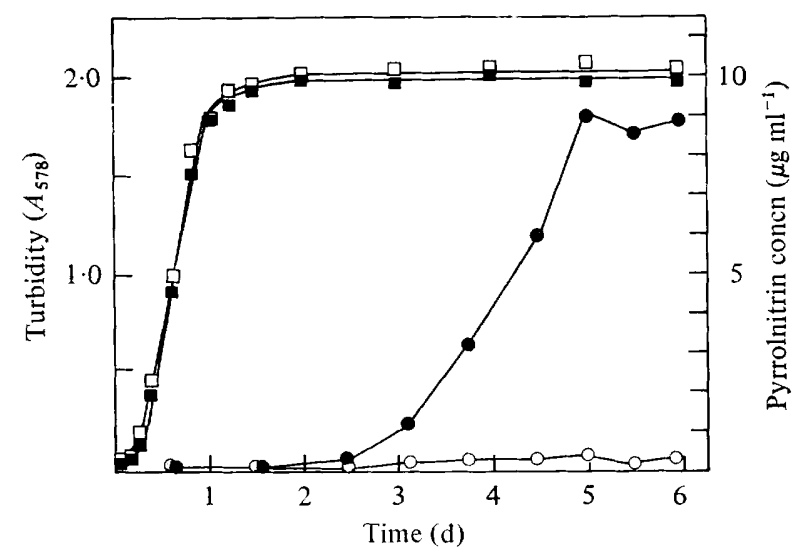

Fig. 1. Pyrrolnitrin formation during growth of the wild-type and of the mutant strain ACN of $P$. aureofaciens in glycerol minimal medium. Pyrrolnitrin concentrations in cultures of the wild-type strain $(\bigcirc)$ and of the mutant strain $\mathrm{ACN}(\odot)$ in relation to the growth curves [wild-type $(\square)$, mutant ACN (匚)] were assayed as described in Methods.

\section{Table 1. Growth rates of the wild-type and of the mutant strain ACN of $P$. aureofaciens on various carbon sources}

Bacteria were grown in minimal salts medium with the carbon source indicated ( $3 \mathrm{~mm}$ ) as described in Methods.

\begin{tabular}{lcc} 
& \multicolumn{2}{c}{ Generation time (h) } \\
\cline { 2 - 3 } Carbon source & Wild-type strain & Mutant strain ACN \\
Glycerol & 1.9 & 1.9 \\
L-Tryptophan & $4 \cdot 0$ & 37.9 \\
L-Kynurenine & 4.5 & $40 \cdot 0$ \\
Anthranilic acid & 4.6 & no growth
\end{tabular}

Colonies of the mutant strain were colourless, while those of the parent strain were yellow-orange. However, as described below, both strains were able to produce phenazine1-carboxylic acid. The lack of pigmentation in the mutant strain might indicate that it is unable to synthesize 2-hydroxyphenazine-1-carboxylic acid, which is known to be the yellow-orange pigment of $P$. aureofaciens (Olson \& Richards, 1967).

The mutant strain grew extremely slowly on L-tryptophan as the sole source of carbon and nitrogen (Table 1). This slow growth was not due to the appearance of revertants but to the utilization of the side-chain of the L-kynurenine formed. A blue fluorescent compound accumulated in large amounts during growth on L-tryptophan; this was identified as anthranilic acid. Anthranilic acid was metabolized by the parent strain but not by the mutant strain. D-Tryptophan, indole-3-acetic acid and indole were not used by either strain.

Compounds from divergent pathways of tryptophan metabolism were isolated to examine whether substitution patterns were altered in the metabolites produced by the mutant. Anthranilic acid, aminopyrrolnitrin, indole-3-acetic acid, phenazine-1-carboxylic acid and pyrrolnitrin were isolated from cultures of 101 batches of both strains. Ultraviolet, infrared (results not shown) and mass spectra were identical for the compounds isolated from the culture media of both strains and for the reference compounds (Table 2). Mixed melting points showed no depression. The increased antibiotic activity is therefore not due to the synthesis of a new, biologically more active pyrrolnitrin.

3-Chloroanthranilic acid and 7-chloroindole-3-acetic acid were isolated from the cultures of both strains (Salcher \& Lingens, 1978).

In the fluorescent group of pseudomonads only $P$. syringae ( $P$. savastanoi) has been reported to synthesize indole-3-acetic acid (Maggie et al., 1963). 
Table 2. Metabolites from divergent pathways of tryptophan catabolism isolated from the wild-type and mutant strain ACN of P. aureofaciens

Pseudomonas aureofaciens ATCC 15926 and P. aureofaciens ACN were grown in glycerol minimal medium, supplemented with 3 mM-L-tryptophan or D-tryptophan, if necessary, for optimal production of metabolites. Isolation and identification procedures are described in Methods. The intensities of the mass spectra peaks are expressed as percentages and the first peak given for each compound corresponds to the mass peak.

\begin{tabular}{|c|c|c|c|c|}
\hline Metabolite & $\begin{array}{l}\text { Supplement } \\
\text { to growth } \\
\text { medium }\end{array}$ & $\begin{array}{c}\text { Ultraviolet } \\
\text { absorption maxima } \\
\text { in methanol }(\mathrm{nm})\end{array}$ & $\begin{array}{l}\text { Mass spectrum } \\
\text { peaks }(m / e)\end{array}$ & $\begin{array}{l}\text { Melting point } \\
(\text { decomp.) } \\
\left({ }^{\circ} \mathrm{C}\right)\end{array}$ \\
\hline Anthranilic acid & L-Tryptophan & $313,242,210$ & $\begin{array}{l}137(52 \%) \\
119(100 \%)\end{array}$ & 145 \\
\hline Aminopyrrolnitrin & D-Tryptophan & 300,210 & $\begin{array}{l}226(77 \%) \\
228(45 \%) \\
230(9 \%) \\
156(100 \%)\end{array}$ & 85 \\
\hline Indole-3-acetic acid & None & $289,280,272,219$ & $\begin{array}{l}175(58 \%) \\
130(100 \%)\end{array}$ & 165 \\
\hline Phenazine-1-carboxylic acid & None & 368,252 & $\begin{array}{l}224(4 \%) \\
180(100 \%)\end{array}$ & 235 \\
\hline Pyrrolnitrin & D-Tryptophan & 252 & $\begin{array}{l}256(55 \%) \\
258(30 \%) \\
260(6 \%) \\
166(100 \%)\end{array}$ & 123 \\
\hline
\end{tabular}

The increased production of pyrrolnitrin may be considered in relation to the flow of metabolites by different pathways from the common precursor, tryptophan. The mutant strain was not capable of using anthranilic acid as sole carbon source. This compound arises from the benzene moiety of tryptophan. Thus, in the mutant one of several pathways competing with pyrrolnitrin synthesis is probably at least partially blocked.

We thank Dr D. Spitzner and G. Schwinger for recording the mass spectra and the Fonds der Chemischen Industrie for support.

\section{REFERENCES}

Adelberg, E. A., Mandel, M. \& Chen, G. C. C. (1965). Optimal conditions for mutagenesis by $N$-methyl- $N^{\prime}$-nitro- $N$-nitrosoguanidine in Escherichia coli K-12. Biochemical and Biophysical Research Communications 18, 788-795.

Arima, K., ImanaKa, H., Kousaka, M., Fukuda, A. \& Tamura, G. (1964). Pyrrolnitrin, a new antibiotic substance, produced by Pseudomonas. Agricultural and Biological Chemistry 28, 575-576.

Auden, J., Gruner, J., Nüesch, J. \& KNüsel, F. (1967). Some statistical methods in nutrient medium optimalization. Pathologia et microbiologia 30, 858-866.

Buchanan, R. E. \& GibBons, N. E. (editors) (1974). Bergey's Manual of Determinative Bacteriology, 8th edn. Baltimore: Williams \& Wilkins.

Drew, S. W. \& Demain, A. L. (1977). Effect of primary metabolites on secondary metabolism. Annual Review of Microbiology 31, 343-356.

Elander, R. P. (1976). Mutation to increased product formation in antibiotic producing microorganisms. In Microbiology, pp. 453-466. Edited by D. Schlessinger. Washington: American Society for Microbiology.
Elander, R. P., Mabe, J. A., Hamill, R. L. \& GoRMAN, M. (1968). Metabolism of tryptophans by Pseudomonas aureofaciens. VI. Production of pyrrolnitrin by selected Pseudomonas species. Applied Microbiology 16, 753-758.

Elander, R. P., Mabe, J. A., Hamill, R. L. \& Gorman, M. (1971). Biosynthesis of pyrrolnitrins by analogue-resistant mutants of Pseudomonas fluorescens. Folia microbiologica 16, 156-165.

Gordee, R. S. \& WeSTHEAd, J. (1972). Pyrrolnitrin. Analytical Microbiology 2, 329-338.

HAMill, R. L., Elander, R. P., Mabe, J. \& Gorman, M. (1967). Metabolism of tryptophans by Pseudomonas aureofaciens. V. Conversion of tryptophan to pyrrolnitrin. Antimicrobial Agents and Chemotherapy, 388-396.

Lively, D. H., Gorman, M., Haney, M. E. \& MABE, J. (1967). Metabolism of tryptophans by Pseudomonas aureofaciens. I. Biosynthesis of pyrrolnitrin. Antimicrobial Agents and Chemotherapy, 462-469.

LYSENKO, O. (1961). Pseudomonas - an attempt at a general classification. Journal of General Microbiology 25, 379-408. 
Maggie, A. R., Wilson, E. E. \& Kosuge, T. (1963). Indoleacetamide as an intermediate in the synthesis of indoleacetic acid in Pseudomonas savastanoi. Science 141, 1281-1282.

Martin, L. L., Chang, C.-J., Floss, H. G., HagaMAN, E. W. \& WENKERT, E. (1972). A ${ }^{13}$ C-nuclear magnetic resonance study on the biosynthesis of pyrrolnitrin from tryptophan by Pseudomonas. Journal of the American Chemical Society 94, 8942-8944.

Olson, E. \& RichaRds, J. H. (1967). The structure of the orange pigment from Pseudomonas aureofaciens. Journal of Organic Chemistry 32, 2887 2890.

SAlCher, O. \& Lingens, F. (1978). Biosynthese von Pyrrolnitrin. Nachweis von 3-Chloranthranilsäure und 7-Chlorindolessigsäure im Kulturmedium von Pseudomonas aureofaciens. Tetrahedron Letters 34, 3101-3102.
Salcher, O., Lingens, F. \& Fischer, P. (1978). Biosynthese von Pyrrolnitrin. Nachweis von 4(2'-Amino-3'-chlorphenyl)pyrrol-2-carbonsäure. Tetrahedron Letters 34, 3097-3100.

SCHRöTER, R. (1957). Reduktion der Nitrogruppe mit Natrium-dithionit. In Methoden der Organischen Chemie (Houben-Weyl), 4th edn, vol. 11, pp. 437--442. Edited by E. Müller. Stuttgart: G. Thieme Verlag.

Skerman, V. B. D. (1967). A Guide to the Identification of the Genera of Bacteria, 2nd edn. Baltimore: Williams \& Wilkins.

Society OF AMERICAN BACTERIOLOGISTS (1957). Manual of Microbiological Methods. New York: McGraw-Hill.

Stahl, E. \& Kaldewey, H. (1961). Spurenanalyse physiologisch aktiver, einfacher Indolderivate. Hoppe-Seyler's Zeitschrift für physiologische Chemie 323, 182-191. 